\title{
A Basin-Wide Survey of Coastal Wetlands of the Laurentian Great Lakes: Development and Comparison of Water Quality Indices
}

\author{
Anna M. Harrison ${ }^{1}$ (1) - Alexander J. Reisinger ${ }^{1,2} \cdot$ Matthew J. Cooper $^{3} \cdot$ Valerie J. Brady $^{4} \cdot$ Jan J. H. Ciborowski ${ }^{5}$. \\ Katherine E. $\mathrm{O}^{\prime}$ Reilly $^{6}$ • Carl R. Ruetz $\mathrm{III}^{7}$ - Douglas A. Wilcox ${ }^{8}$ - Donald G. Uzarski ${ }^{1}$
}

Received: 22 March 2019 / Accepted: 1 July 2019 / Published online: 5 August 2019

(C) The Author(s) 2019

\begin{abstract}
Coastal wetlands of the Laurentian Great Lakes are vital habitats for biota of ecological and economic importance. These habitats are susceptible to water quality impairments driven by runoff from the landscape due to their location along the shoreline. Monitoring of the overall status of biotic and abiotic conditions of coastal wetlands within the Great Lakes has been ongoing for over a decade. Here, we utilize measurements of aquatic physicochemical and land cover variables from 877 vegetation zones in 511 coastal wetland sites spanning the US and Canadian shorelines of the entire Great Lakes basin. Our objective is to develop water quality indices based on physicochemical measures (Chem-Rank), land use/land cover (LULC-Rank), and their combined effects (Sum-Rank and Simplified Sum-Rank), for both vegetation zones and wetland sites. We found that water quality differed among wetland vegetation types and among Great Lakes regions, corroborating previous findings that human land use alters coastal wetland water quality. Future monitoring can use these straightforward, easy-to-calculate indices to assess the abiotic condition of aquatic habitats. Our data support the need for management efforts focused on reducing nutrient and pollution loads that stem from human activities, particularly in the developed southern portions of the Great Lakes basin.
\end{abstract}

Keywords Water quality index $\cdot$ Coastal wetland $\cdot$ Great Lakes $\cdot$ Anthropogenic $\cdot$ Disturbance $\cdot$ Land use

\section{Introduction}

In recent decades, aquatic resource managers have increasingly used biological indicators to assess ecosystem health, in place of chemical and physical sampling of habitats, inferring that biota integrate conditions over time, whereas chemical and physical samples represent only a snapshot of the ecosystem. Published references to biological indicators have

Electronic supplementary material The online version of this article (https://doi.org/10.1007/s13157-019-01198-z) contains supplementary material, which is available to authorized users.

Anna M. Harrison

harri25a@cmich.edu

1 Institute for Great Lakes Research and Biology Department, Central Michigan University, Mount Pleasant, MI 48859, USA

2 Soil and Water Sciences Department, University of Florida, Gainesville, FL 32611, USA

3 Burke Center for Freshwater Innovation, Northland College, Ashland, WI 54806, USA increased over the last 20 years, with many new biological indices developed for aquatic ecosystems (Ruaro and Gubiani 2013). Biological indices are developed based on the underlying assumption that the suite of anthropogenic impacts on an ecosystem can be best represented by the biological community capable of persisting within that ecosystem (Karr 1981). Ecosystems with taxa sensitive to physical and chemical stressors are assumed to have experienced fewer

4 Natural Resources Research Institute, University of Minnesota Duluth, Duluth, MN 55811, USA

5 Department of Biological Sciences, University of Windsor, Windsor, Ontario N9B 3P4, Canada

6 Department of Biological Sciences, University of Notre Dame, Notre Dame, IN 46556, USA

7 Annis Water Resources Institute, Grand Valley State University, Muskegon, MI 49441, USA

8 Department of Environmental Science and Ecology, SUNY College at Brockport, Brockport, NY 14420, USA 
anthropogenic impacts and thus be of higher quality. Although this index of biotic integrity (IBI) approach is wellestablished, it remains difficult to differentiate the relative influence of anthropogenic disturbances in biological communities from effects of natural disturbances (Suter 2001), although some watershed modeling approaches have assessed these relationships (Wiley et al. 2003). In coastal wetlands of the Laurentian Great Lakes (hereafter, Great Lakes), for example, anthropogenic disturbances can mask or interact with the effects of natural disturbances, such as wave exposure (Burton et al. 2004) or water-level fluctuations (Wilcox et al. 2002), on community structure.

As a contrast to the IBI approach, physicochemical measurements in water (which include both chemical and physical variables) can be used to infer anthropogenic disturbances on an ecosystem more directly. Unfortunately, physicochemical measurements often fail to detect habitat alterations, and individual water chemistry or physical metrics may not reveal specific anthropogenic disturbances. Further, the effect of a disturbance on the entire ecosystem can persist longer than detectable changes in water quality. Although acute disturbances such as pulses of point-source contaminant discharge may not be detectable over long periods, chronic anthropogenic disturbances (e.g., increased nutrient and sediment loadings that accompany agricultural land use and urban development) have been associated with altered water quality across Great Lakes coastal wetlands (Chow-Fraser 2006; Morrice et al. 2008). These anthropogenic disturbances also influence the scores of macroinvertebrate- and fish-based IBIs within Great Lakes coastal wetlands (Uzarski et al. 2004, 2005; Cooper et al. 2018).

In addition to physicochemical measurements, the land use surrounding aquatic ecosystems often provides an indicator of anthropogenic stress, and multiple indices of land use stress within the Great Lakes basin have been developed. For example, Danz et al. (2007) developed a shoreline stress index for the U.S. shoreline of the Great Lakes by combining five classes of stressors (i.e., agriculture, atmospheric deposition, human population, land cover, and point-source pollution). Host et al. (2011) developed a stress index for the entirety of Lake Superior using land use/land cover, population density, point-source discharge, and road density. This stress index was spatially expanded to create a watershed stress index for the entire Great Lakes Basin, as part of the State of the Lakes Ecosystem Conference (Brown et al. 2017). Further research assessed the influences of these watershed-based stressors on established responses of various species assemblages in coastal areas of the Great Lakes (Host et al. 2019).

Efforts to combine landscape variables with water chemistry and physical variables typically focus on a driver-response relationship (e.g., Chow-Fraser 2006), but these two types of indices are rarely combined in a monitoring framework. Combined water quality and land use indices can be useful in understanding habitat quality in Great Lakes coastal wetlands because these two approaches allow for direct estimation of current in situ water quality (physical and chemical conditions in water) and inference of the longer term surrogate measure of chronic pollution (land use). Water quality data are also easy to collect, can require less specialized collection expertise and equipment than an IBI, and are often available online through a variety of monitoring programs (e.g., governmental agencies, non-profit organizations, or universities).

The habitat condition and water quality of Great Lakes coastal wetlands can influence the capacity of coastal wetlands to provide beneficial functions. Coastal wetlands are biodiverse ecosystems that serve as a major component of nearshore lake nutrient cycling. They also filter pollutants and other contaminants running off the landscape that would otherwise imperil the pelagic biota of the Great Lakes (Uzarski et al. 2017 and references therein). Despite their ecological importance, nearly half of all coastal wetland areas in the Great Lakes have been converted to other land uses (e.g., agriculture, development) since European settlement, and many remaining wetlands are threatened by multiple anthropogenic stressors (Maynard and Wilcox 1997; Environment Canada and the U.S. Environmental Protection Agency 2014).

Since 2011, a basin-wide monitoring effort has been underway to quantify the overall ecological status of coastal wetlands in the Laurentian Great Lakes using standardized, quantitative methods. This monitoring program has provided data on the abiotic and biotic conditions of coastal wetlands to a range of stakeholders (Uzarski et al. 2017). Our primary objective in this study is to use physicochemical data collected from the coastal wetland monitoring project (see Uzarski et al. 2017), coupled with landscape metrics, to develop an overall view of coastal wetland water quality along U.S. and Canadian shorelines throughout the entire Great Lakes basin. We previously proposed an index of anthropogenic disturbance combining physicochemical and landscape stressors (Uzarski et al. 2005), but this previous index was limited in its spatial scale. Taken individually, specific indices of water quality or landscape stress have the potential to miss or overlook either acute or chronic signatures of anthropogenic impairments. Thus, we predict that the combination of landscape-level and physicochemical metrics is likely to capture a wider range of anthropogenic disturbances than consideration of either stressor type individually.

We also anticipate spatial variability within each indicator metric because water quality will vary both locally among vegetation types and regionally across the Great Lakes basin. Wetland vegetation taxa have variable tolerances for anthropogenic disturbances, including water quality (Lougheed et al. 2001), to the extent that vegetation communities can be used as indicators of wetland health (Albert and Minc 2004; Croft and Chow-Fraser 2007; Grabas et al. 2012). Specifically, we expect to see lower water quality scores in Phrgamites and 
Typha vegetation zones (Albert and Minc 2004; Zedler and Kercher 2004) compared to vegetation zones dominated by native vegetation, especially those with lower tolerances to anthropogenic disturbance (e.g., Schoenoplectus) (Croft and Chow-Fraser 2007).

\section{Methods}

\section{Site Selection and Description}

We performed field sampling between mid-June and early September from 2011 through 2015 as part of a coordinated, basin-wide, coastal wetland monitoring program (greatlakeswetlands.org). We used a stratified-random site-selection procedure to select a subset of all accessible coastal wetlands identified throughout the Great Lakes to sample each year (see Uzarski et al. 2017 for a detailed description of site identification and sampling approach). We measured a suite of physicochemical (physical and chemical) and biological variables at each site using a variety of sampling methods (Uzarski et al. 2017 and references therein). Here, we focus on aquatic physicochemical variables and landscape metrics to understand the drivers of overall water quality in Great Lakes coastal wetlands.

Per the program-wide sampling protocols, at each site we visually identified all mono-dominant vegetation habitat types consisting of at least $75 \%$ of a single category of wetland vegetation. Each site could have multiple mono-dominant habitat types, which we refer to as vegetation zones. Emergent vegetation zones were typically mono-dominant, whereas SAV and wet meadow were generally mixtures of different taxa. Submerged aquatic vegetation (SAV) zones were established where SAV was present, but there was not any floating or emergent vegetation (Uzarski et al. 2017). Over the 5-year period, we sampled 1114 vegetation zones from 518 unique sites, but for this analysis, we only include vegetation types that accounted for $>1 \%$ of all vegetation zones sampled (i.e., we excluded extremely rare vegetation types). Ten vegetation types were included in this analysis: wet meadow (dominated by sedges; Carex, Juncus, and Eleocharis), Typha, Phragmites, mixed emergent (no dominant emergent vegetation type), Peltandra/Sagittaria/ Pontederia (PSP, combined due to similar growth form), Sparganium, Zizania (wild rice), Schoenoplectus (bulrush), Nuphar-Nymphaea (lily), and submerged aquatic vegetation (SAV) (Table 1). Where data were missing from a location (i.e., the $12 \%$ of zones missing one or two physicochemical measurements from the rank indices), we substituted the mean value of the variable estimated from values measured within all other zones. This procedure allowed us to maintain the same sample size for the rank calculations without influencing the final rank of the zone or site. Ultimately, we included 877 unique vegetation zones from 511 unique sites (Table 1).

\section{Landscape Characteristics}

We used the North American Land Change Monitoring System (NALCMS) 2010 land cover of North America at $30 \mathrm{~m}$ to provide land cover data for each site (CEC 2015). To assess both local and regional land cover, we extracted land cover estimates from $1-\mathrm{km}$ and $20-\mathrm{km}$ buffers around each wetland site. Distance buffers allowed for a standardized land cover estimate across different wetland classes (lacustrine, barrier-protected, and riverine). We extracted four land cover categories from the NALCMS classes, including \%-natural vegetation (forest + grassland + shrub), \%-developed (urban), $\%$-agricultural (cropland), and \%-wetland.

\section{Aquatic Physicochemical Characteristics}

At each vegetation zone, we measured a suite of physical and chemical variables in situ at the middle of the water column. Using YSI (or similar) multi-parameter sondes, we measured in situ water temperature, $\mathrm{pH}$, specific conductance $(\mu \mathrm{S}$ $\mathrm{cm}^{-1}$ ), and dissolved oxygen (DO concentration; $\mathrm{mg} \mathrm{L}^{-1}$ and $\%$ saturation). We calibrated data sondes prior to sampling according to manufacturer protocols and a stringent quality assurance project plan that is followed by all field staff for the coastal wetland monitoring program (Uzarski et al. 2017; greatlakeswetlands.org). We also collected a composite water sample (of 3 sub-samples) within each vegetation zone in an acid-washed carboy and stored samples on ice until returning from the field. We measured water clarity in the field using a sub-sample of this water sample with a $100-\mathrm{cm}$ transparency tube (Anderson and Davie 2004).

In the laboratory, we analyzed the water sample from each vegetation zone for a range of analyses using standard methods. We transferred two unfiltered water samples into $250-\mathrm{mL}$, acid-washed polypropylene bottles and stored these samples frozen for later analysis of total nitrogen (TN; mg $\mathrm{L}^{-1}$ ) and total phosphorus (TP; $\mathrm{mg} \mathrm{L}^{-1}$ ) using standard methods (APHA 2005). An additional subsample was filtered through a Whatman GF/C glass fiber filter and frozen for later analysis. We then thawed and analyzed the glass fiber filter for chlorophyll $a\left(\mathrm{chl} a ; \mu \mathrm{g} \mathrm{L}^{-1}\right.$ ) using standard methods (APHA 2005). We further filtered the filtrate from the chl $a$ sample through an acid- and deionized water (DI)-rinsed $0.45-\mu \mathrm{m}$ Millipore membrane filter into an acid-washed, DI-rinsed polypropylene bottle and subsequently froze the sample. We later thawed and analyzed this sample for soluble reactive phosphorus ( $\mathrm{SRP}, \mathrm{mg} \mathrm{L}^{-1}$ ), ammonium-N $\left(\mathrm{NH}_{4}^{+}-\mathrm{N}, \mathrm{mg}\right.$ $\left.\mathrm{L}^{-1}\right)$, and [nitrate + nitrite]- $\mathrm{N}\left(\mathrm{NO}_{3}{ }^{-}-\mathrm{N}, \mathrm{mg} \mathrm{L}^{-1}\right)$ via standard methods (APHA 2005). 
Table 1 Ten vegetation types (rows, $n=877$ ) were sampled across ten regions (columns, $n=511$ ) in the Great Lakes

\begin{tabular}{|c|c|c|c|c|c|c|c|c|c|c|c|}
\hline Vegetation (Veg.) Type & $\begin{array}{l}\text { LE } \\
\text { North }\end{array}$ & $\begin{array}{l}\text { LE } \\
\text { South }\end{array}$ & $\begin{array}{l}\text { LH } \\
\text { North- } \\
\text { east }\end{array}$ & $\begin{array}{l}\text { LH } \\
\text { South- } \\
\text { west }\end{array}$ & $\begin{array}{l}\text { LH } \\
\text { West }\end{array}$ & $\begin{array}{l}\text { LM } \\
\text { North }\end{array}$ & $\begin{array}{l}\text { LM } \\
\text { South }\end{array}$ & $\begin{array}{l}\text { LO } \\
\text { North }\end{array}$ & $\begin{array}{l}\text { LO } \\
\text { South }\end{array}$ & LS & $\begin{array}{l}\text { No. of } \\
\text { Veg. } \\
\text { Zones }\end{array}$ \\
\hline Bulrush & 2 & 3 & 33 & 12 & 59 & 28 & 1 & 9 & 6 & 34 & 187 \\
\hline Lily & 4 & 23 & 13 & 3 & 12 & 13 & 8 & 22 & 20 & 20 & 138 \\
\hline Mixed Emergent & 1 & 0 & 1 & 0 & 6 & 1 & 0 & 0 & 0 & 7 & 16 \\
\hline $\begin{array}{l}\text { Peltandra, Sagataria, Pontidaria } \\
\text { (PSP) }\end{array}$ & 1 & 7 & 2 & 1 & 1 & 1 & 1 & 3 & 8 & 7 & 32 \\
\hline Phragmites & 8 & 11 & 3 & 15 & 10 & 12 & 0 & 0 & 0 & 0 & 59 \\
\hline $\begin{array}{l}\text { Submerged Aquatic Vegetation } \\
\text { (SAV) }\end{array}$ & 11 & 7 & 11 & 1 & 3 & 24 & 3 & 43 & 40 & 25 & 180 \\
\hline Sparganium & 2 & 0 & 1 & 0 & 0 & 1 & 0 & 0 & 0 & 11 & 15 \\
\hline Typha & 9 & 18 & 19 & 6 & 32 & 38 & 3 & 5 & 1 & 32 & 163 \\
\hline Wet Meadow & 0 & 1 & 33 & 0 & 15 & 9 & 0 & 0 & 0 & 15 & 73 \\
\hline Wild Rice & 0 & 0 & 2 & 0 & 0 & 2 & 0 & 6 & 0 & 4 & 14 \\
\hline No. Veg. Zones per Region & 38 & 71 & 119 & 38 & 138 & 129 & 16 & 90 & 82 & 156 & 877 \\
\hline No. Unique Sites per Region & 25 & 36 & 76 & 21 & 79 & 67 & 11 & 62 & 55 & 79 & 511 \\
\hline
\end{tabular}

The ten regions were defined by first by country and ecoregion (Southern U.S., Northern U.S., and Canada) and then divided by lake: two regions in Lake Erie (LE North and South), three regions in Lake Huron (LH Northeast, Southwest and West), two regions in Lake Michigan (LM North and South), two regions in Lake Ontario (LO North and South), and the entirety of Lake Superior (LS)

\section{Index Development}

Four water quality indices were calculated and compared in this study: (1) Chem-Rank Index, an index based only on physicochemical variables, (2) LULC-Rank Index, an index based only on land use/land cover data, (3) Simplified-Sum Rank Index (SS-Rank), a simplified index comprised of both physicochemical and land cover variables, and (4) the original Sum Rank Index (Sum-Rank), which includes a more complex combination of physicochemical and land cover variables than SS-Rank (Uzarski et al. 2005; Uzarski et al. 2017). The Chem-Rank index and LULC-Rank index highlight the relative contributions of each to the Sum-Rank and SS-Rank indices.

Because many of the physicochemical and land cover variables were non-normally distributed and expressed on different scales, we rank-transformed each variable prior to index development. Ranks were assigned to variables such that rank order was proportionate to the inferred degree of anthropogenic disturbance. Variables with high values indicative of low disturbance (i.e., water clarity, $\%$ natural vegetation and \% wetland land cover) were ranked ascendingly, with high ranks given to high values. For example, at the site level, a water clarity rank of 511 was given to the site with the clearest water, and a rank of 1 was given to the site with the lowest water clarity. High values of variables indicative of high disturbance (i.e., specific conductance, $\mathrm{NO}_{3}{ }^{-}{ }^{-} \mathrm{N}, \mathrm{NH}_{4}{ }^{+}-\mathrm{N}$, SRP, $\mathrm{TN}, \mathrm{TP}, \mathrm{chl} a, \%$ developed land cover, $\%$ agricultural land cover) were scaled such that higher values received lower ranks. For example, a SRP rank of 1 was given to the site with the highest SRP concentration (or highest disturbance), whereas a rank of 511 was given to the site with the lowest SRP concentration. We acknowledge that nutrients occur naturally in these systems (i.e., without human inputs); however, the majority of nitrogen and phosphorous inputs come from anthropogenic sources.

Rank values for all the variables at both the vegetation zone level and site level were then summed for index calculation. We scaled each summed index value from 0 to 100, using Eq. 1 , where 'Rank ${ }_{i}$ ' is the summed rank value for each site or vegetation zone and 'Rank min $^{\text {' and 'Rank }}$ max $_{\text {' }}$ are the corresponding lowest and highest ranked site or zone within each index. Separate scales were derived for vegetation zone (based on 877 observations) and for site (based on 511 observations).

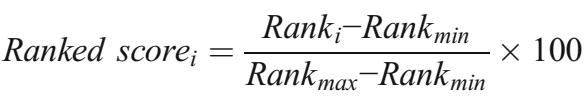

Chem-Rank was calculated by summing individual ranks for eight physicochemical variables (specific conductance, $\mathrm{NO}_{3}{ }^{-}-\mathrm{N}, \mathrm{NH}_{4}{ }^{+}-\mathrm{N}, \mathrm{SRP}, \mathrm{TN}, \mathrm{TP}, \mathrm{chl} a$, and water clarity). The Chem-Rank index was measured at both the vegetation zone and site level. Although chloride is an important indicator of anthropogenic influences in water quality, it was not included in the indices because it was not measured at all sites in our dataset. Values of specific conductance and chloride were strongly positively correlated within vegetation zones where both variables were measured $(r=0.82)$. Specific conductance serves as a valuable surrogate for anthropogenic inputs of chloride, and thus is a useful metric of anthropogenic 
disturbance in our indices. We included both total (TN, TP) and dissolved $\left(\mathrm{NO}_{3}{ }^{-}-\mathrm{N}, \mathrm{NH}_{4}{ }^{+}-\mathrm{N}, \mathrm{SRP}\right)$ nutrients in our water quality indices because each form of inorganic (or organic) nutrient can affect an ecosystem differently. For nitrogen, $\mathrm{NH}_{4}{ }^{+}-\mathrm{N}$ is typically more biologically available than $\mathrm{NO}_{3}{ }^{-}-$ $\mathrm{N}$, whereas $\mathrm{NO}_{3}{ }^{-}-\mathrm{N}$ represents the majority of dissolved inorganic nitrogen and can readily alleviate $\mathrm{N}$ limitation. For phosphorous, SRP is bioavailable, whereas TP is tied up in biological material and can correlate with suspended sediments (Grayson et al. 1996; Baustian et al. 2018).

We calculated a land use/land cover only index, LULCRank, to assess the contribution of only land cover to potential effects on water quality. The LULC-Rank was calculated by summing the ranks of all eight LULC variables calculated from the NALCMS (1-km and 20-km buffers for $\%$ developed, $\%$ natural vegetation, $\%$ agriculture, $\%$ wetland). We calculated LULC-Rank at the site level only because different vegetation zones at the same site have identical LULC values.

The SS-Rank index was developed as a combination of in situ physicochemical variables and land cover. It is a simplified index, developed from the original and more complex Sum-Rank (described below). SS-Rank summed the ranks of the eight physicochemical variables in Chem-Rank with the ranks of the eight land cover ranks from LULC-Rank, giving each index equal weight in SS-Rank. SS-Rank was calculated at both the vegetation zone and site levels.

Our original water quality index, Sum-Rank, contained all the same variables as the SS-Rank index described above, but included two additional categories of variables. The first category consisted of variables ranked based on distance from the median (i.e., more extreme values were indicative of disturbance). This extreme-value approach was used to rank $\mathrm{NO}_{3}{ }^{-}$ $\mathrm{N}, \mathrm{DO}$, and $\mathrm{pH}$ in Sum-Rank, but was removed from SS-Rank to simplify the index calculations and because the median nutrient concentrations from on our dataset are generally higher than what is expected from a natural system without anthropogenic sources. The second additional category in Sum-Rank was a multivariate ordination, Principal Component Analysis (PCA), calculated from raw values of all physicochemical variables and land cover proportions, and then scaled so that higher PC1 values indicated higher ranking (Uzarski et al. 2005). The PCA was also omitted from SS-Rank, to minimize calculation steps required for the simplified index.

\section{Analyses}

Indices developed at the vegetation zone level were calculated from values measured within each individual vegetation zone at each site $(n=877)$. Vegetation type averages for water quality are available in Online Resource 1. We used linear mixed effects models to test for statistically significant differences in water quality across vegetation type (Table 1) and included region as a random effect for each model to account for regional spatial variability of vegetation types. To define the ten regions, the Great Lakes basin was divided into three broad regions by country and ecoregion (Bailey and Cushwa 1981; Omernik 1987): Southern U.S., Northern U.S., and Canada. Each region was then divided by lake, with the entirety of Lake Superior as one region because there were so few wetlands on the northern side of Lake Superior. Vegetation type group means were compared using a Tukey post-hoc multiple comparisons test. Differences among vegetation types were calculated for only three indices (SS-Rank, Sum-Rank, and Chem-Rank) because LULC was only calculated at the site level. The lme4 package (Bates et al. 2015) was used for linear mixed effects models and the emmeans package (Lenth 2018) for subsequent Tukey multiple comparison tests. All statistical analyses and figure preparations were performed in $\mathrm{R}$ (version 3.5.0; R Development Core Team 2018).

For site-level indices, we averaged each variable's raw values for all vegetation zones sampled within an individual site to calculate site-level values and ranks $(n=511)$. Regional average values for water quality variables and land cover are available in Online Resources 2 and 3. We then used analysis of variance (ANOVA) to test whether water quality differed across Great Lakes regions (Table 1) using the site-level SSRank, Sum-Rank, Chem-Rank, and LULC-Rank indices and compared groups using a Tukey post-hoc test.

At the site level, we also quantified the strength of relationships between the six pairs of four indices (SS-Rank, SumRank, Chem-Rank, and LULC-Rank) using Pearson's correlation. We then compared individual variables included in Chem-Rank or LULC-Rank with the alternate index using Pearson's correlation with a Bonferroni correction for multiple comparisons. For example, we quantified the correlation between water clarity and LULC-Rank, as well as the correlation between developed land cover in the $20-\mathrm{km}$ buffer with Chem-Rank. We did not compare individual variables with their associated index (e.g., $\mathrm{NO}_{3}{ }^{-} \mathrm{N} \sim \mathrm{Chem}$-Rank) due to autocorrelation. For correlation analyses, we $\log _{10}$-transformed all physicochemical variables that fit a log-normal distribution (all variables except clarity), and we arcsinesquare root transformed land cover variables due to nonnormal distributions.

\section{Results}

SS-Rank, Sum-Rank, and Chem-Rank all varied across vegetation types, and all indices had the highest average value in bulrush zones (Fig. 1, Online Resource 4). The SS-Rank differed across vegetation types (LMER; $\mathrm{F}_{9}, 859=9.012$; $p<0.001)$, ranging from an average of $43.5( \pm 25.5 \mathrm{SD})$ in Phragmites zones to 71.1 ( \pm 14.7 SD) in bulrush zones (Fig. 1a). In post-hoc multiple comparison tests, bulrush zones had higher index values than Lily $(p<0.001)$, PSP $(p=0.024)$, 
Phragmites $(p<0.001)$, SAV $(p<0.001)$, and Typha $(p<0.001)$ zones; and wet meadow zones had higher values than zones of Phragmites $(p=0.023)$ and Typha $(p<0.001$; Fig. 1a). The Sum-Rank index ranged, on average, from 44.4 ( \pm 24.7 SD) in Phragmites to 69.6 ( \pm 14.5 SD) in bulrush zones and differed across vegetation types (LMER; $\mathrm{F}_{9,869}=$ 8.137 ; $p<0.001$; Fig. 1b). In a multiple comparison test, bulrush zones had higher values than Lily $(p<0.001)$, PSP ( $p=$ $0.022)$, Phragmites $(p<0.001), \operatorname{SAV}(p<0.001)$, and Typha zones $(p<0.001)$; wet meadow zones had higher values than Typha zones ( $p=0.004$; Fig. 1b). The physicochemical index (Chem-Rank) values ranged, on average, from $48.6( \pm 21.3$ SD) in PSP zones to 73.1 ( $\pm 13.8 \mathrm{SD})$ in bulrush zones and differed across vegetation types (LMER; $F_{9}, 861=7.91$; $p<0.001$ ), despite large variation within a given vegetation type (Fig. 1c). A multiple comparison test revealed that bulrush zones had higher Chem-Rank values than Lily $(p<0.001)$, PSP $(p=0.003)$, Phragmites $(p<0.001)$, SAV $(p=0.003)$, Typha $(p<0.001)$, and wet meadow zones $(p=$ 0.034; Fig. 1c). All other post-hoc multiple comparisons were not significant at $\alpha=0.05$ (Fig. 1, Online Resource 5).

All four indices varied at the site level across Great Lakes regions. Each index had the lowest average value in northern Lake Erie (LE North) and the highest average in western Lake Huron (LH West), with the exception of the LULC-Rank, which was highest in Lake Superior (Fig. 2, Online Resource 6). SS-Rank values averaged from $20.2( \pm$ $17.5 \mathrm{SD})$ to $75.8( \pm 10.9 \mathrm{SD})$ and varied among regions (ANOVA; $\mathrm{F}_{9,501}=72.59 ; p<0.001$; Fig. $2 \mathrm{a}$ ). Sum-Rank values ranged, on average, from $22.5( \pm 16.9 \mathrm{SD})$ to 74.5 ( \pm $10.5 \mathrm{SD}$ ) across sites and differed among regions (ANOVA; $\mathrm{F}_{9,501}=71.66$; $p<0.001$; Fig. 2b). Chem-Rank averages ranged across Great Lakes regions from 28.7 ( $\pm 22.6 \mathrm{SD})$ to $72.8( \pm 12.0 \mathrm{SD})$, and values varied among regions (ANOVA; $\mathrm{F}_{9,501}=29.55 ; p<0.001 ;$ Fig. $2 \mathrm{c}$ ). Regional averages for the land cover index (LULC-Rank) ranged from $14.6( \pm 13.1 \mathrm{SD})$ in LE North to 74.1 ( \pm 15.0 SD) in Lake Superior, and index values differed among regions (ANOVA; $\mathrm{F}_{9}, 501=98.35$; $p<0.001$; Fig. 2d). Overall trends across all rank indices show the lowest water quality and land cover quality at sites in Lake Erie, southern Lake Michigan, and southwestern Lake Huron. Lake Superior, northern Lake Michigan, and western and northeastern Lake Huron had the highest ranked scores for both water quality and land cover across all four indices (Fig. 2, Fig. 3, Online Resources 6, 7). Chem-Rank had the greatest variability among regions compared to the other three rank indices (Fig. 2, Online Resource 6, 7).

Chem-Rank was correlated with seven of the eight landcover variables included in LULC-Rank, had positive correlations with natural vegetation and $20 \mathrm{~km}$ wetland land cover, and had negative correlations with both developed and agricultural land cover (Table 2). Of the LULC variables, ChemRank was most negatively correlated with the $20-\mathrm{km}$ agricultural land cover $(\mathrm{r}=-0.51)$ and most positively correlated with $20-\mathrm{km}$ natural vegetation $(\mathrm{r}=0.55)$. LULC-Rank was negatively correlated with all the physicochemical variables included in Chem-Rank, except water clarity with which it was positively correlated (Table 2). The strongest LULCRank correlation with a physicochemical variable was with specific conductance $(\mathrm{r}=-0.64)$.

Unsurprisingly, the four indices were correlated with each other (Fig. 4). The SS-Rank and Sum-Rank were highly correlated with one another $(r=0.98$; Fig. $4 a)$, and SS-Rank had slightly higher correlations with Chem-Rank $(r=0.88$; Fig. 4c) and LULC-Rank ( $r=0.90$; Fig. 4e) compared with SumRank correlations with Chem-Rank $(r=0.85$; Fig. $4 d)$ and LULC-Rank ( $r=0.89$; Fig. $4 \mathrm{f})$. These results suggest that SS-Rank may be a suitable and easier to calculate and interpret alternative to the Sum-Rank.

There was a fair amount of variability in the relationship between Chem-Rank and LULC-Rank $(r=0.58)$, and the variability in Chem-Rank values was greater at low LULC-Rank values $(<40)$ compared to higher LULC-Rank values (Fig. 4b). This variability shows that these two indices are not explaining identical water quality impairments. It also demonstrates that, although land use/land cover represents the potential for stress, it is not necessarily indicative of actual stressors in the ecosystems. In addition, the variability may be illustrating differences in temporal and spatial stresses, where the water quality (one point in time) does not match the land cover (large area, relatively unchanging in the long-term). Therefore, the development of SS-Rank and Sum-Rank from Chem-Rank and LULC-Rank provides additional information that may not be evident from only one of the individual indices.

\section{Discussion}

\section{Basin-Wide Water Quality Patterns}

Water quality impairment has been identified as an important factor contributing to wetland degradation (Morrice et al. 2008; Cvetkovic and Chow-Fraser 2011). There is interest among natural resource managers in protecting and restoring coastal wetlands in the Great Lakes, including the chemical and physical nature of these systems (Mitsch and Wang 2000), with hopes that improving coastal wetland water quality may both enhance habitat for biota and reduce pollution loads into open water areas of the adjacent lakes. Our analyses of water quality in 877 vegetation zones from 511 unique coastal wetlands represents the largest inventory of water quality monitoring data from Great Lakes coastal wetlands. Our results confirm previous findings of poor water quality in coastal wetlands in portions of the more heavily-populated southern Great Lakes basin, with generally higher water quality in the 

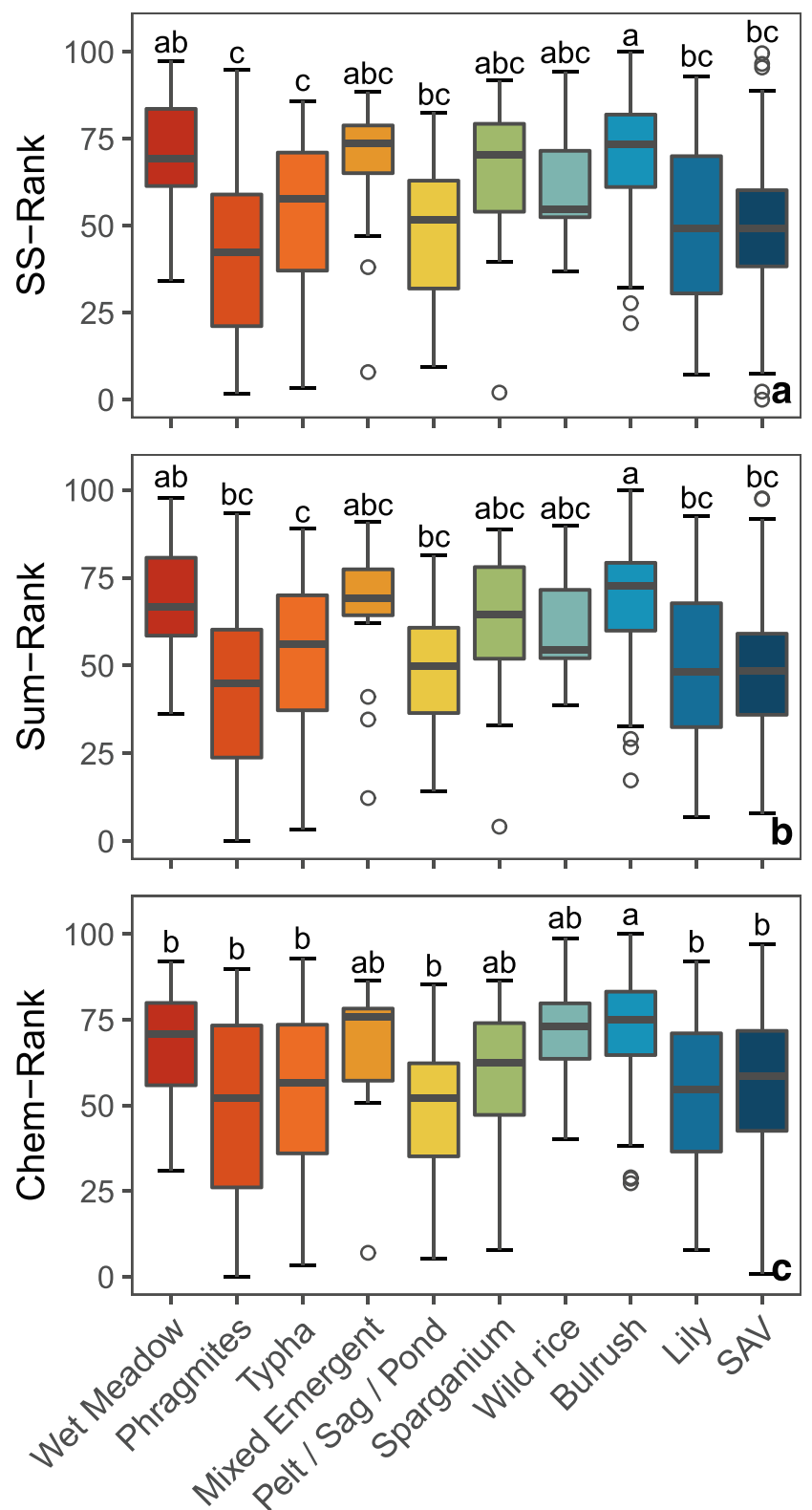

Fig. 1 Water quality indices (SS-Rank; a, Sum-Rank; b and Chem-Rank; c) differed among vegetation types in linear mixed effects models, despite large variation both within and among zone types. High index scores on the $y$-axis indicate high quality vegetation types (labeled on the x-axis), whereas low scores indicate low quality vegetation types. Different letters atop error bars reflect significant differences $(\alpha=0.05)$ among vegetation types from Tukey multiple comparison tests. A total of 877 individual vegetation zones from ten common vegetation types were sampled; each vegetation type is represented by a different color. Values for means and standard deviations of ranks by vegetation type are available in Online Resource 4

northern portions of the basin (Chow-Fraser 2006; Cvetkovic and Chow-Fraser 2011; Uzarski et al. 2017).

The spatial distribution of vegetation types within coastal wetlands (i.e., within sites) also supports the trend of higher water quality in the northern Great Lakes. The vegetation types with highest index scores (bulrush and wet meadow) were found predominantly ( $82 \%$ and $99 \%$, respectively) in the four northern regions with the highest SS-Rank index scores (northeastern and western Lake Huron, northern Lake Michigan, and Lake Superior). It is unclear, however, if these factors are mechanistically related or if they reflect the influence of another extrinsic driver not included in the present analysis. Bulrush occur throughout the Great Lakes basin; thus, this trend likely reflects lower anthropogenic disturbance (water quality impairments among other potential disturbances) in the northern regions compared with southern regions. Bulrush zones may also be prevalent in higher quality northern sites because they are outside the area of Phragmites invasion at northern latitudes and because bulrushes tolerate the low nutrient concentrations that inhibit both Phragmites and Typha dominance (Albert and Minc 2004; Lemein et al. 2017). This latitudinal trend may explain the lower overall variability in rank values within the bulrush zones compared to the high variability in the five vegetation zones with the lowest average rank values: Lily, PSP, Phragmites, SAV, and Typha. This indicates that while vegetation zone presence is related to region, these relationships are likely a product of the plant community response to the amount of anthropogenic disturbance at a site, which generally trends along a latitudinal gradient in the Great Lakes.

Despite this general latitudinal trend, water quality in coastal wetlands near anthropogenically impacted areas in the northern basin, such as Duluth, MN, was also poor (Fig. 3). This pattern of poor water quality in wetlands located closer to human activity is further supported by the negative correlations found between Chem-Rank and agricultural and developed land cover using both $1-\mathrm{km}$ and $20-\mathrm{km}$ buffers (Table 2). The 20-km land cover buffers have stronger correlations with the water quality endpoints than the $1-\mathrm{km}$ buffers. This is possibly a product of the land use directly adjacent to the coast $(1-\mathrm{km}$ buffer) being non-representative of the surrounding land use, and the $20-\mathrm{km}$ buffer likely better represents what is loading into the wetlands. For example, in Saginaw Bay, some coastal wetlands have narrow buffers of forested land use around the wetland, but the majority of the land use in the $20-\mathrm{km}$ buffer is agriculture. This influence of agricultural and urban land use on nutrient loading from tributaries has been modeled at broad scales in the Great Lakes basin (Bosch et al. 2011; Robertson and Saad 2011), and empirical studies have consistently shown a negative relationship between water quality and land use (Chow-Fraser 2006; Trebitz et al. 2007; Morrice et al. 2008). Our study provides additional, complementary indices of water quality to assess Great Lakes coastal wetlands based on a large sample of sites along both the U.S. and Canadian shorelines. 

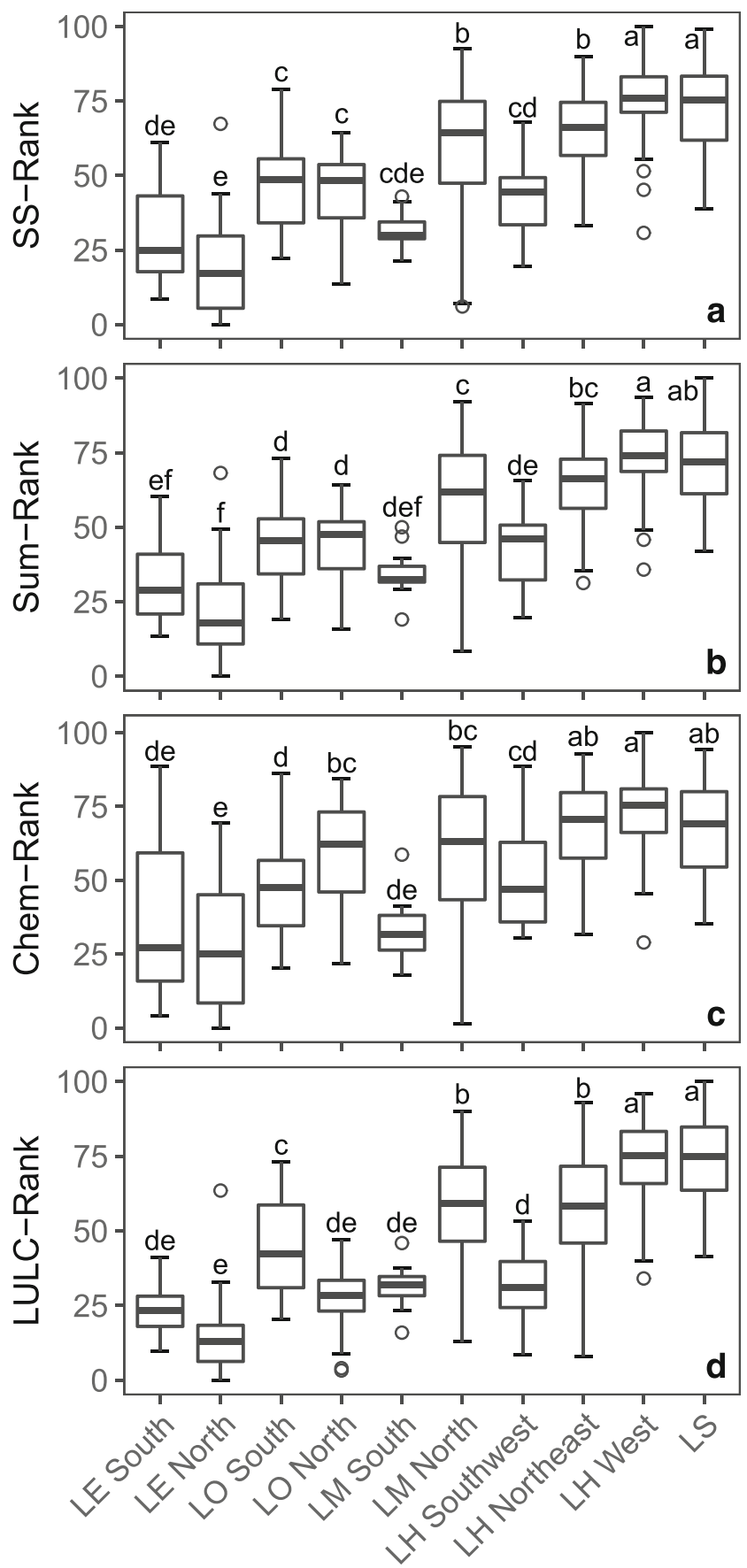

Fig. 2 Water quality indices based on combinations of physicochemical and land cover variables (SS-Rank; a and Sum-Rank; b), physicochemical variables only (Chem-Rank; c), and land cover only (LULC-Rank; d) differed among Great Lakes regions in one-way ANOVAs. High index scores on the $y$-axis indicate high quality sites, compared to low y-axis values that indicate sites with poorer water quality. Letters denote differences among regions from Tukey HSD post-hoc tests. Regions were broken into ten geographic areas (labeled on the x-axis), described in Table 1. Values for means and standard deviations of ranks by region are available in Online Resource 6

Most of the physicochemical variables measured correlated negatively with LULC-Rank values (all except water clarity), indicating that wetlands surrounded by higher proportions of agricultural and developed land cover had lower water quality. Specific conductance was most strongly (negatively) correlated with LULC-Rank values, whereas various dissolved nutrient metrics (i.e., $\mathrm{NO}_{3}{ }^{-}, \mathrm{NH}_{4}{ }^{+}, \mathrm{SRP}$ ) were less correlated with LULC-Rank values (Table 2). Although $\mathrm{N}$ and $\mathrm{P}$ concentrations were high in many wetlands, coastal wetland algal biofilms are frequently nutrient-limited, and $\mathrm{N}$-limitation appears to be more common than P-limitation (Cooper et al. 2016). If N-limitation is common across coastal wetlands, then internal cycling may explain the fairly weak relationship between dissolved inorganic N and LULC-Rank values. Dissolved inorganic nutrients are highly labile, and internal cycling can significantly alter dissolved nutrient concentrations in coastal wetlands (Krieger 2003; Morrice et al. 2004). Total nutrient concentrations (TN or TP) showed stronger negative relationships with LULC-Rank values than dissolved inorganic forms, further reflecting the role of internal biogeochemical cycling of nutrients within wetlands.

\section{Strengths of the Index Approach}

Assessments of ecological condition of aquatic habitats can address needs that may range from individual management questions related to specific drivers of environmental quality to broad-scale surveys intended to provide a general overview of a range of environmental conditions. Our goal in deriving the SS-Rank index was to create a simple metric to characterize water quality, based on easily measured variables, that is intuitive to formulate and easy to understand and interpret. Previously developed environmental indices tend to rely primarily on either water quality (Chow-Fraser 2006) or landscape data (Danz et al. 2007). Our results highlight the explanatory value of incorporating water quality monitoring with land use/land cover data for water quality index development. Although we found significant correlations between our physicochemical- and landscape-based sub-indices, there was considerable residual variation in the relationship (Fig. $4 \mathrm{~b}$ ), suggesting that combining both factors provides more information than either one individually.

The combination of both water quality variables and land cover allowed our indices to distinguish both regional (e.g., southern vs. northern Green Bay, eastern vs. western Lake Ontario) and basin-wide (e.g., northern vs. southern latitudes) gradients in wetland water quality (Fig. 3) and to identify areas where land cover is less predictive of water quality. For example, the average Chem-Rank index score was significantly higher in northern Lake Ontario $(59.5 \pm 17.7 \mathrm{SD})$ than in four other regions (northern and southern Lake Erie, southern Lake Michigan, and southern Lake Ontario), whereas the LULCRank index score for northern Lake Ontario was much lower $(27.9 \pm 9.0 \mathrm{SD})$ than the Chem-Rank value, and the LULCRank was not significantly different from the lowest ranked regions (Fig. 2). This suggests that despite northern Lake 
Ontario having a higher proportion of developed and agricultural land cover, the effects of these land uses are not reflected as strongly in physicochemical variables (i.e., Chem-Rank) compared with other regions. Conversely, the Duluth area of western Lake Superior has higher LULC-Rank values than Chem-Rank values, which also indicates that land use/land cover alone is not necessarily a good predictor of water quality (Fig. 3c, d). This area has high shipping traffic and associated anthropogenic disturbances that influence water quality yet are not accounted for in the land cover buffers. It is also possible that not all the upstream land use influencing these wetlands is accounted for in the $20-\mathrm{km}$ land use buffer in this particular area.

An additional strength of our SS-Rank approach is its relative simplicity. In contrast to previous indices put forth by our research group (e.g., Uzarski et al. 2005; the original SumRank index described in this paper), the SS-Rank index is based solely on the rank-order of variables and not multivariate ordinations or median-centered values. Although multivariate approaches may capture patterns in environmental gradients that univariate approaches do not, the use of ordinations can complicate the development and interpretation of an index and make it difficult to establish which individual factors drive patterns within a given index. The removal of mediancentered values also simplifies the SS-Rank index, compared to the Sum-Rank index. This was justified after univariate regressions found that relationships with physicochemical variables were not improved by transforming their values based on distance from the median. Dissolved oxygen and $\mathrm{pH}$ can also vary throughout the day (Nelson et al. 2009), which further justifies their removal in SS-Rank index. Therefore, to maximize the simplicity of the SS-Rank index, we ranked absolute values of $\mathrm{NO}_{3}{ }^{-} \mathrm{N}$ (rather than their distance from the median) and removed DO and $\mathrm{pH}$ from the SS-Rank.
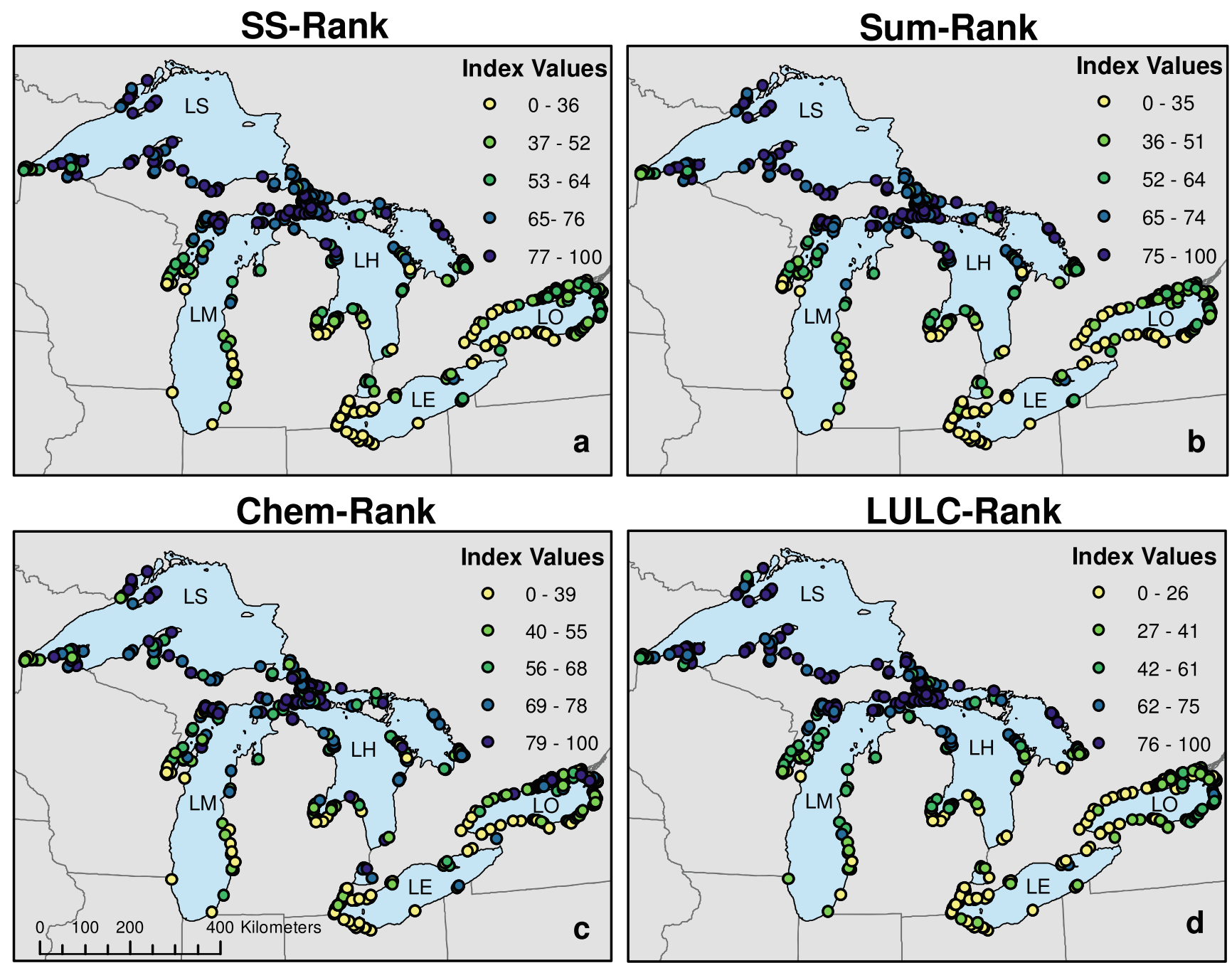

Fig. 3 Spatial distribution of index scores were mapped across the entire Great Lakes basin (SS-Rank; a, Sum-Rank; b, Chem-Rank; c and LULCRank; d). Each point represents a unique coastal wetland site. Rank values were equally divided into five sub-classes to represent water

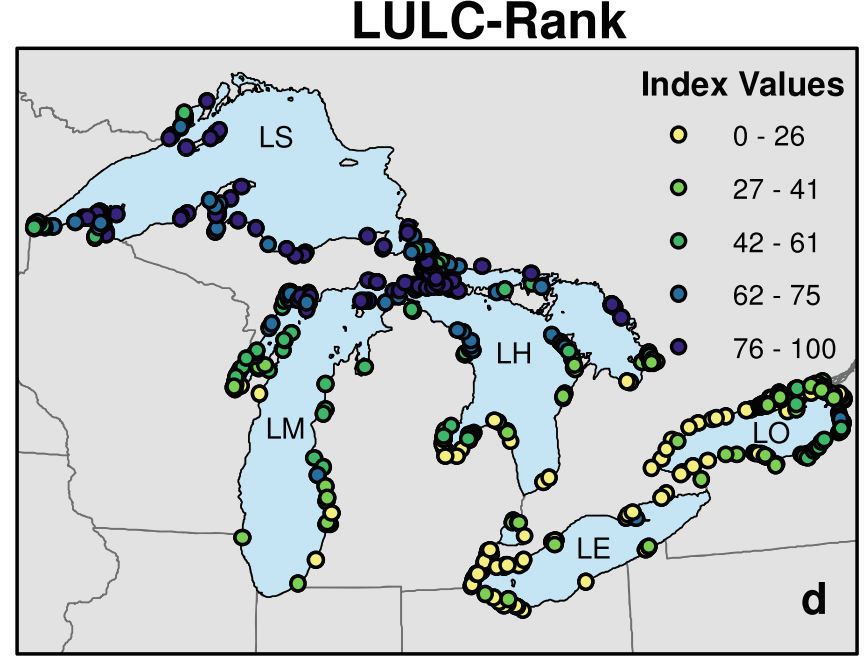

quality status. Water quality ranges from light yellow-colored points representing the poorest water quality (low numbers) to dark bluecolored points representing the highest water quality (high numbers) 
Table 2 Pearson's $r$ correlations between individual aquatic physicochemical or land use/land cover variables and the alternate index of water quality (LULCRank or Chem-Rank) at the site level $(\mathrm{n}=511)$

\begin{tabular}{|c|c|c|}
\hline & $\mathrm{r}$ & $p$ \\
\hline Physicochemical & \multicolumn{2}{|c|}{ LULC-Rank } \\
\hline Clarity & 0.23 & $<0.001$ \\
\hline Spec. Cond ${ }^{\mathrm{a}}$ & -0.64 & $<0.001$ \\
\hline $\mathrm{TN}^{\mathrm{a}}$ & -0.45 & $<0.001$ \\
\hline $\mathrm{NO}_{3}-\mathrm{N}^{\mathrm{a}}$ & -0.11 & 0.092 \\
\hline $\mathrm{NH}_{4}{ }^{+}-\mathrm{N}^{\mathrm{a}}$ & -0.21 & $<0.001$ \\
\hline $\mathrm{TP}^{\mathrm{a}}$ & -0.58 & $<0.001$ \\
\hline $\mathrm{SRP}^{\mathrm{a}}$ & -0.43 & $<0.001$ \\
\hline $\mathrm{Chl} a^{\mathrm{a}}$ & -0.39 & $<0.001$ \\
\hline Land Cover & \multicolumn{2}{|c|}{ Chem-Rank } \\
\hline $\mathrm{Ag} 20 \mathrm{~km}^{\mathrm{b}}$ & -0.51 & $<0.001$ \\
\hline $\mathrm{Ag} 1 \mathrm{~km}^{\mathrm{b}}$ & -0.37 & $<0.001$ \\
\hline Dev20 km ${ }^{b}$ & -0.48 & $<0.001$ \\
\hline Dev1 $\mathrm{km}^{\mathrm{b}}$ & -0.35 & $<0.001$ \\
\hline NatVeg20km ${ }^{\mathrm{b}}$ & 0.55 & $<0.001$ \\
\hline NatVeg $1 \mathrm{~km}^{\mathrm{b}}$ & 0.40 & $<0.001$ \\
\hline Wetland $20 \mathrm{~km}^{\mathrm{b}}$ & 0.27 & $<0.001$ \\
\hline Wetland $1 \mathrm{~km}^{\mathrm{b}}$ & 0.11 & 0.103 \\
\hline
\end{tabular}

The $p$ values reflect Bonferroni correction for multiple comparisons

${ }^{\text {a }} \log _{10}$ transformed

${ }^{\mathrm{b}}$ Arcsine-square root transformed
Our simplified indices are still consistent with values of the ordination-based Water Quality Index (WQI) proposed by Chow-Fraser (2006), as we found strong correlations between the WQI and both SS-Rank and Chem-Rank using our sitelevel data $(r=0.81$ and $r=0.86$, respectively). The ChemRank index had a higher correlation than SS-Rank with the WQI, likely because the WQI is calculated from water quality variables only, and SS-Rank also incorporates land cover. Our SS-Rank builds upon the WQI by including land-cover proportions in the index calculation in addition to physicochemical variables.

\section{Applications of Rank Indices}

As a broadly adaptable tool, the SS-Rank index could be applied to assess habitat quality in other systems and regions, rather than just coastal wetlands in the Laurentian Great Lakes. Because our index is based on univariate rankings and then scaled from zero to 100 , a subset of variables could be used to calculate the index rather than requiring measurement of all physicochemical variables included in the full index. To assess the quality of freshwater coastal wetland ecosystems using this index, we recommend that, at minimum, specific conductance, TN, TP, and chlorophyll $a$ (measured via standard methods, APHA 2005) be included, along with all land cover data. These variables are all strongly associated with anthropogenic disturbance and have previously been shown to drive water quality of coastal wetlands (Crosbie and Chow-Fraser 1999; Trebitz et al. 2007; Morrice et al. 2008). Although chloride was not included in the rank indices in this paper, we recommend its inclusion, if possible, but suggest that specific conductance is also an excellent metric for anthropogenic disturbances, as it is easy to measure and correlates with multiple disturbance metrics.

In combining physicochemical and land cover variables across a large spatial scale, the SS-Rank index also provides government agencies in Canada and the U.S. with an updated tool to assess progress towards achieving the objectives agreed upon in the Great Lakes Water Quality Agreement (GLWQA), "to restore and maintain the chemical, physical, and biological integrity of the waters of the Great Lakes Basin Ecosystem" (United States and Canada 1978). The SS-Rank index could be used as a tool to meet obligations outlined in the GLWQA annexes, as each annex contains specific requirements, and the SS-Rank could be applied to the goals of several annexes (e.g., Annex 2, Lakewide Management; Annex 7, Habitat and Species; and Annex 10, Science). For example, Annex 10, Science calls for signatories to establish, maintain, and update comprehensive, science-based ecosystem indicators to assess the state of the Great Lakes and measure progress toward achievement of the objectives of the GLWQA. The SS-Rank index could provide managers with an indicator of coastal wetland health that could be used to assess changes over time in wetland health throughout the region.

\section{Conclusions}

The Laurentian Great Lakes basin spans a vast geographic area, including a range of climates, geology, and land use. The densest human land use (agricultural + developed) generally occurs in the southern portion of the basin, but all five lakes have areas that have been substantially altered by human activity. In our survey, which encompasses the largest number of Great Lakes coastal wetlands surveyed to date and is comprised of wetlands along both the U.S. and Canadian shorelines, we revealed patterns of coastal wetland water quality associated with land use and land cover alterations that complement previous studies. Such water quality impairments have been associated with changes to biological communities inhabiting Great Lakes coastal wetlands, including macrophytes (Lougheed et al. 2001; Croft and Chow-Fraser 2007), macroinvertebrates (Uzarski et al. 2004; Cooper et al. 2007), and fishes (Uzarski et al. 2005; Seilheimer and Chow-Fraser 2006; Cooper et al. 2018). A focus on improving water quality in coastal wetlands is vital to enhance habitat for biota and reduce pollution loads to open-water habitats of the Great Lakes. Our results, together with previous studies, indicate that reducing nutrient loading from human activities on the landscape (e.g., agriculture and 

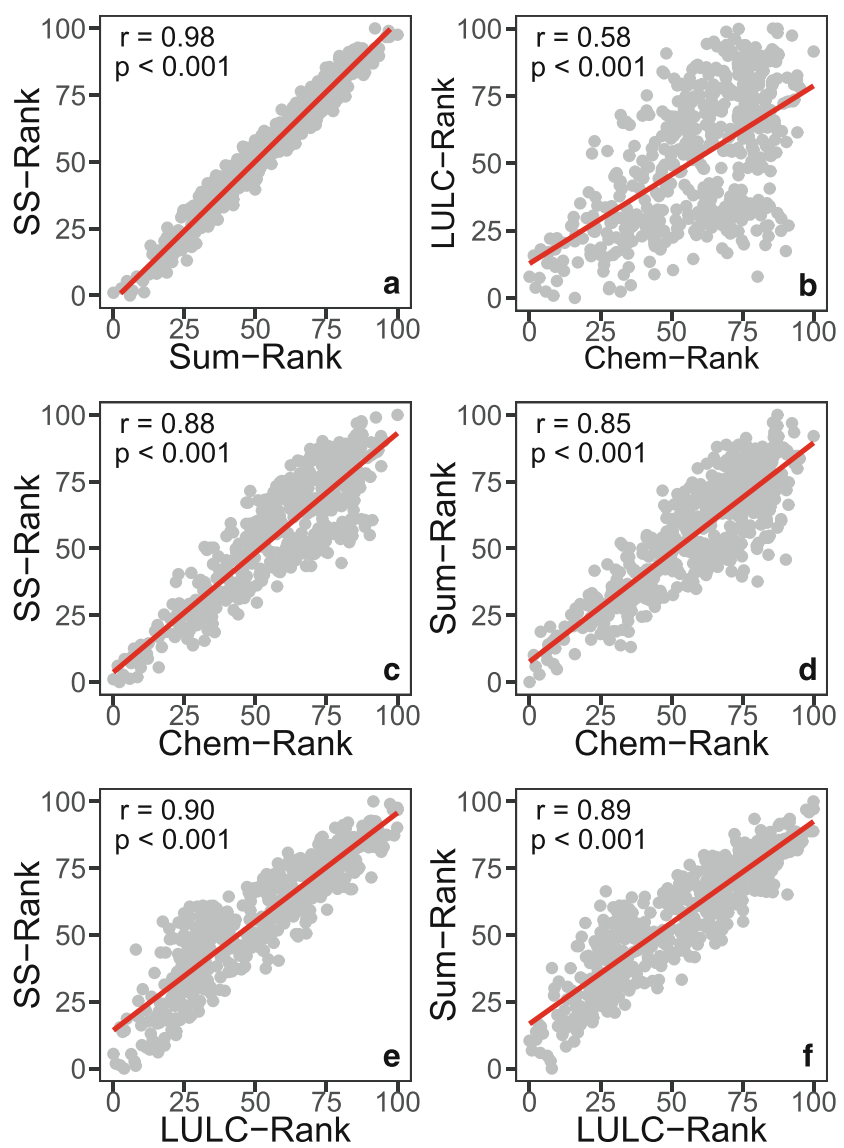

Fig. 4 All four water quality indices were correlated with the other indices. Gray points represent unique coastal wetland sites. The trendline (red line) and correlation statistics ( $r$ and $p$ value) are provided in each panel. SS-Rank and Sum-Rank showed a strong correlation (a), whereas LULC-Rank and Chem-Rank were moderately correlated (b). High correlations in the bottom four panels $(\mathbf{c}, \mathbf{d}, \mathbf{e}, \mathbf{f})$ are based on the incorporation of variables from both Chem-Rank and LULC-Rank in the calculation of Sum-Rank and SS-Rank

urbanization) is critical for improving water quality. Best management practices designed to minimize nutrient application rates (e.g., soil testing) and retain nutrients and other pollutants on the land prior to downstream export (e.g., riparian buffers) are essential to protecting and improving abiotic and biotic conditions of coastal wetlands, as well as the overall ecological functioning of the Great Lakes.

Acknowledgments The data contributing to this paper were collected by scientists and their research teams from 11 U.S. and Canadian universities, three U.S. and Canadian government agencies, and one environmental engineering and science firm. The U.S. project team consists of scientists from Central Michigan University's Institute for Great Lakes Research, the Natural Resources Research Institute (NRRI) at the University of Minnesota Duluth, the Annis Water Resources Institute (AWRI) at Grand Valley State University, the Burke Center for Freshwater Innovation at Northland College, the University of Notre Dame, Lake Superior State University, State University of New YorkCollege at Brockport, the University of Wisconsin at Green Bay, River Falls, and Superior, and Oregon State University, as well as resource management officials from the Michigan Department of Environmental Quality and the United States Environmental Protection Agency
(USEPA), and a data-management professional from LimnoTech. Canadian scientists are from the University of Windsor, Environment and Climate Change Canada, and Bird Studies Canada. Funding was provided by the Great Lakes National Program Office under the USEPA, grant number GL-00E00612-0, as part of the US federal government's Great Lakes Restoration Initiative. Although this research is partly funded by USEPA, it has not been subjected to the agency's required peer and policy review. Thus, it does not necessarily reflect the views of the agency and no official endorsement should be inferred. This paper is Contribution Number 128 of the Central Michigan University Institute for Great Lakes Research.

Open Access This article is distributed under the terms of the Creative Commons Attribution 4.0 International License (http:// creativecommons.org/licenses/by/4.0/), which permits unrestricted use, distribution, and reproduction in any medium, provided you give appropriate credit to the original author(s) and the source, provide a link to the Creative Commons license, and indicate if changes were made.

\section{References}

Albert DA, Minc LD (2004) Plants as regional indicators of great lakes coastal wetland health. Aquatic Ecosystem Health and Management 7:233-247. https://doi.org/10.1080/14634980490461588

Anderson P, Davie RD (2004) Use of transparency tubes for rapid assessment of total suspended solids and turbidity in streams. Lake and Reservoir Management 20:110-120. https://doi.org/10.1080/ 07438140409354355

APHA (2005) Standard methods for the examination of water and wastewater, 25th edn. American Public Health Association, Washington D.C.

Bailey RG, Cushwa CT (1981) Ecoregions of North America (map). (FWS/OBS-81/29.) Washington, DC: U.S. Fish and Wildlife Service. 1:12,000,000

Bates D, Maechler M, Bolker B, Walker S (2015) Fitting linear mixedeffects models using lme4. Journal of Statistical Software 67:1-48. https://doi.org/10.18637/jss.v067.i01

Baustian JJ, Kowalski KP, Czayka A (2018) Using turbidity measurements to estimate Total phosphorus and sediment flux in a Great Lakes coastal wetland. Wetlands 38:1059-1065. https://doi.org/10. 1007/s13157-018-1044-3

Bosch NS, Allan JD, Dolan DM, Han H, Richards RP (2011) Application of the soil and water assessment tool for six watersheds of Lake Erie: model parameterization and calibration. Journal of Great Lakes Research 37:263-271. https://doi.org/10.1016/j.jglr.2011.03.004

Brown TN, Johnson LB, Host GE, Ciborowski JJH (2017) Sub-Indicator - Watershed Stressors. In: State of the Great Lakes 2017 Technical Report. Cat No. En161 3/1E PDF. EPA 905 R 17 001. Environment and Climate Change Canada and the U.S. Environmental Protection Agency. pp 437-461

Burton TM, Uzarski DG, Genet JA (2004) Invertebrate habitat use in relation to fetch and plant zonation in northern Lake Huron coastal wetlands. Aquatic Ecosystem Health \& Management 7:249-267. https://doi.org/10.1080/14634980490461614

Chow-Fraser P (2006) Development of the water quality index (WQI) to assess effects of basin wide land use alteration on coastal marshes of the Laurentian Great Lakes. In: Simon TP, Stewart PM (eds) Coastal wetlands of the Laurentian Great Lakes: health, habitat and indicators. Author House, Bloomington, pp 137-166

Commission for Environmental Cooperation (CEC): Canada Centre for Remote Sensing (CCRS), Earth Sciences Sector, Natural Resources 
Canada, Comisión Nacional para el Conocimiento y Uso de la Biodiversidad (CONABIO), Comisión Nacional Forestal (CONAFOR), Insituto Nacional de Estadística y Geografía (INEGI), and U.S. Geological Survey (USGS) (2015) North American land change monitoring system (NALCMS). Available via http://www.cec.org/tools-and-resources/map-files/land-cover2010-landsat-30m. Accessed 1 June 2019

Cooper MJ, Uzarski DG, Burton TM (2007) Macroinvertebrate community composition in relation to anthropogenic disturbance, vegetation, and organic sediment depth in four Lake Michigan drowned river-mouth wetlands. Wetlands 27:894-903. https://doi.org/10. 1672/0277-5212(2007)27[894:MCCIRT]2.0.CO;2

Cooper MJ, Costello GM, Francoeur SN, Lamberti GA (2016) Nitrogen limitation of algal biofilms in coastal wetlands of lakes Michigan and Huron. Freshwater Science 35:25-40. https://doi.org/10.1086/ 684646

Cooper MJ, Lamberti GA, Moerke AH, Ruetz CR, Wilcox DA, Brady VJ, Brown TN, Ciborowski JJH, Gathman JP, Grabas GP, Johnson LB (2018) An expanded fish-based index of biotic integrity for Great Lakes coastal wetlands. Environmental Monitoring and Assessment 190:580. https://doi.org/10.1007/s10661-018-6950-6

Croft MV, Chow-Fraser P (2007) Use and development of the wetland macrophyte index to detect water quality impairment in fish habitat of Great Lakes coastal marshes. Journal of Great Lakes Research 33: 172-198. https://doi.org/10.3394/0380-1330(2007)33[172: UADOTW]2.0.CO;2

Crosbie B, Chow-Fraser P (1999) Percentage land use in the watershed determines the water and sediment quality of 22 marshes in the Great Lakes basin. Canadian Journal of Fisheries and Aquatic Sciences 56:1781-1791. https://doi.org/10.1139/f99-109

Cvetkovic M, Chow-Fraser P (2011) Use of ecological indicators to assess the quality of Great Lakes coastal wetlands. Ecological Indicators 11:1609-1622. https://doi.org/10.1016/j.ecolind.2011. 04.005

Danz NP, Niemi GJ, Regal RR, Hollenhorst T, Johnson LB, Hanowski JAM, Axler RP, Ciborowski JJH, Hrabik T, Brady VJ, Kelly JR, Morrice JA, Brazner JC, Howe RW, Johnston CA, Host GE (2007) Integrated measures of anthropogenic stress in the U.S. Great Lakes basin. Environmental Management 39:631-647. https://doi.org/10. 1007/s00267-005-0293-0

Environment Canada and the U.S. Environmental Protection Agency (2014) State of the Great Lakes 2011. Cat No. En161-3/1-2011EPDF. EPA 950-R-13-002. Available via https://binational.net. Accessed 25 Oct 2018

Grabas GP, Blukacz-Richards AE, Pernanen S (2012) Development of a submerged aquatic vegetation community index of biotic integrity for use in Lake Ontario coastal wetlands. Journal of Great Lakes Research 38:243-250. https://doi.org/10.1016/j.jglr.2012.02.014

Grayson RB, Finlayson BL, Gippel CJ, Hart BT (1996) The potential of field turbidity measurements for the computation of total phosphorus and suspended solids loads. Journal of Environmental Management 47:257-267. https://doi.org/10.1006/jema.1996.0051

Host GE, Brown TN, Hollenhorst TP, Johnson LB, Ciborowski JJH (2011) High-resolution assessment and visualization of environmental stressors in the Lake Superior basin. Aquatic Ecosystem Health \& Management 14:376-385. https://doi.org/10.1080/14634988. 2011.625340

Host GE, Kovalenko KE, Brown TN, Ciborowski JJH, Johnson LB (2019) Risk-based classification and interactive map of watersheds contributing anthropogenic stress to Laurentian Great Lakes coastal ecosystems. Journal of Great Lakes Research 45:609-618. https:// doi.org/10.1016/j.jglr.2019.03.008

Karr JR (1981) Assessment of biotic integrity using fish communities. Fisheries 6:21-27. https://doi.org/10.1577/1548-8446(1981) 006<0021:AOBIUF $>2.0 . \mathrm{CO} ; 2$
Krieger KA (2003) Effectiveness of a coastal wetland in reducing pollution of a Laurentian great Lake: hydrology, sediment, and nutrients. Wetlands 23:778-791. https://doi.org/10.1672/0277-5212(2003) 023[0778:EOACWI]2.0.CO;2

Lemein T, Albert DA, Del Giudice TE (2017) Coastal wetland vegetation community classification and distribution across environmental gradients throughout the Laurentian Great Lakes. Journal of Great Lakes Research 43:658-669. https://doi.org/10.1016/j.jglr.2017.04. 008

Lenth, R (2018) Emmeans: Estimated Marginal Means, aka LeastSquares Means. R package version 1.2.4. https:/CRAN.R-project. org/package=emmeans. Accessed 7 Sept 2018

Lougheed VL, Crosbie B, Chow-Fraser P (2001) Primary determinants of macrophyte community structure in 62 marshes across the Great Lakes basin: latitude, land use, and water quality effects. Canadian Journal of Fisheries and Aquatic Sciences 58:1603-1612. https:// doi.org/10.1139/cjfas-58-8-1603

Maynard L, Wilcox DA (1997) Coastal wetlands. In: State of the Lakes Ecosystem Conference 1996. Environment Canada and United States Environmental Protection Agency report 905-R-97-015b. Available via https://archive.epa.gov/solec/web/pdf/coastal wetlands_of_the_great_lakes.pdf. Accessed 12 Jan 2019

Mitsch WJ, Wang N (2000) Large-scale coastal wetland restoration on the Laurentian Great Lakes: determining the potential for water quality improvement. Ecological Engineering 15:267-282. https://oi.org/ 10.1016/S0925-8574(00)00081-1

Morrice JA, Kelly JR, Trebitz AS, Cotter AM, Knuth ML (2004) Temporal dynamics of nutrients $(\mathrm{N}$ and $\mathrm{P})$ and hydrology in a Lake Superior coastal wetland. Journal of Great Lakes Research 30:82-96. https://doi.org/10.1016/S0380-1330(04)70379-2

Morrice JA, Danz NP, Regal RR, Kelly JR, Niemi GJ, Reavie ED, Hollenhorst T, Axler RP, Trebitz AS, Cotter AM, Peterson GS (2008) Human influences on water quality in Great Lakes coastal wetlands. Environmental Management 41:347-357. https://doi.org/ 10.1007/s00267-007-9055-5

Nelson KM, Ruetz CR, Uzarski DG (2009) Colonisation by Dreissena of Great Lakes coastal ecosystems: how suitable are wetlands? Freshwater Biology 54:2290-2299. https://doi.org/10.1111/j.13652427.2009.02265.x

Omernik JM (1987) Ecoregions of the conterminous United States. Map (scale 1:7,500,000). Annals of the Association of American Geographers 77(1):118-125

R Core Team (2018) R: A language and environment for statistical computing. R Foundation for Statistical Computing, Vienna, Austria. URL https://www.R-project.org/. Accessed 7 Sept 2018

Robertson DM, Saad DA (2011) Nutrient inputs to the Laurentian Great Lakes by source and watershed estimated using SPARROW watershed models. Journal of the American Water Resources Association 47:1011-1033. https://doi.org/10.1111/j.1752-1688.2011.00574.x

Ruaro R, Gubiani ÉA (2013) A scientometric assessment of 30 years of the index of biotic integrity in aquatic ecosystems: applications and main flaws. Ecological Indicators 29:105-110. https://doi.org/10. 1016/j.ecolind.2012.12.016

Seilheimer TS, Chow-Fraser P (2006) Development and use of the wetland fish index to assess the quality of coastal wetlands in the Laurentian Great Lakes. Canadian Journal of Fisheries and Aquatic Sciences 63:354-366. https://doi.org/10.1139/f05-220

Suter GW (2001) Applicability of indicator monitoring to ecological risk assessment. Ecological Indicators 1:101-112. https://doi.org/10. 1016/S1470-160X(01)00011-5

Trebitz AS, Brazner JC, Cotter AM, Knuth ML, Morrice JA, Peterson GS, Sierszen ME, Thompson JA, Kelly JR (2007) Water quality in Great Lakes coastal wetlands: basin-wide patterns and responses to an anthropogenic disturbance gradient. Journal of Great Lakes Research 33:67-85. https://doi.org/10.3394/0380-1330(2007) 33[67:WQIGLC]2.0.CO;2 
United States and Canada (1978) Great Lakes water quality agreement. Available via: www.ijc.org. Accessed 12 Jan 2019

Uzarski DG, Burton TM, Genet JA (2004) Validation and performance of an invertebrate index of biotic integrity for lakes Huron and Michigan fringing wetlands during a period of lake level decline. Aquatic Ecosystem Health \& Management 7:269-288. https://doi. org/10.1080/14634980490461498

Uzarski DG, Burton TM, Cooper MJ, Ingram JW, Timmermans STA (2005) Fish habitat use within and across wetland classes in coastal wetlands of the five Great Lakes: development of a fish-based index of biotic integrity. Journal of Great Lakes Research 31:171-187. https://doi.org/10.1016/S0380-1330(05)70297-5

Uzarski DG, Brady VJ, Cooper MJ, Wilcox DA, Albert DA, Axler RP, Bostwick P, Brown TN, Ciborowski JJH, Danz NP, Gathman JP, Gehring TM, Grabas GP, Garwood A, Howe RW, Johnson LB, Lamberti GA, Moerke AH, Murry BA, Niemi GJ, Norment CJ, Ruetz CR, Steinman AD, Tozer DC, Wheeler R, O'Donnell TK, Schneider JP (2017) Standardized measures of coastal wetland condition: implementation at a Laurentian Great Lakes basin-wide scale. Wetlands 37:15-32. https://doi.org/10.1007/s13157-0160835-7
Wilcox DA, Meeker JE, Hudson PL, Armitage BJ, Black MG, Uzarski DG (2002) Hydrologic variability and the application of index of biotic integrity metrics to wetlands: a great lakes evaluation. Wetlands 22:588-615. https://doi.org/10.1672/0277-5212(2002) 022[0588:HVATAO]2.0.CO;2

Wiley MJ, Seelbach PW, Wehrly K, Martin J (2003) Regional ecological normalization using linear models: a meta-method for scaling stream assessment indicators. In: Simon TP (ed) Biological response signatures: indicator patterns using aquatic communities. CRC Press Lewis Publishers Inc., Boca Raton, pp 201-223

Zedler JB, Kercher S (2004) Causes and consequences of invasive plants in wetlands: opportunities, opportunists, and outcomes. Critical Reviews in Plant Sciences 23:431-452. https://doi.org/10.1080/ 07352680490514673

Publisher's Note Springer Nature remains neutral with regard to jurisdictional claims in published maps and institutional affiliations. 